\title{
STUDIES ON CARBONIFEROUS INSECTS FROM COMMENTRY, FRANCE: PART IV. THE GENUS TRIPLOSOBA ${ }^{1}$
}

\author{
By F. M. Carpenter \\ Harvard University
}

Among the unusual insects described by Brongniart from the Comimentry shales in France was a nearly complete, well-preserved specimen, apparently related to the mayflies. Now known as Triplosoba pulchella (Brongniart), the species has usually been considered as representing either a distinct order (Protephemerida) or the Order Ephemeroptera itself. In either case, the insect has held a unique position as the oldest representative of the mayfly line of evolution.

This fossil was well described by Brongniart and it has been discussed by Handlirsch (1906), Lameere (I917), Martynov (1923), Tillyard (1932), and Demoulin (1956). Aside from Brongniart, however, only Lameere based his account on an actual study of the fossil itself, the others mentioned depending on published descriptions, figures, or photographs. ${ }^{2}$ Although there has been agreement on the general relationships of Triplosoba, much controversy has existed ovei the interpretation of its venation and consequently of its phylogenetic position within the palaeodictyopterous-ephemeropterous complex. Several of these authors, including Brongniart, have attempted to construct restorations of the complete insect, these also reflecting widely divergent views (see plate 13 ).

The present paper has been written with the hope of eliminating some of the uncertainties and confusion about the structure of Triplosoba. It is based upon my examination of the type specimen of pulchella in the Muséum National d'Histoire Naturelle in Paris. Study of this fossil was made on three separate occasions. The first examination was in 1938, although at that time only one counterpart, the poorer of the two, could be found in the Muséum collection. Following the publication of Demoulin's account of Triplosoba in 1956

\footnotetext{
${ }^{1}$ The preceding part of this series, on the Caloneurodea, was published in Psyche $68: 145-153,1961$. This study has been aided by a National Science Foundation grant.

${ }^{2}$ Demoulin's statement (1956, p. 1), that no new examination of the fossil had been made since Brongniart's description was published in 1893, is certainly an error. Lameere studied the fossil in 1914-15, the results being included in his 1917 summary of the Commentry insects. Demoulin, however, did not examine the specimen itself, but based his conclusions on photographs.
} 
and learning that the other counterpart had subsequently been located in the Muséum, I made an examination of both counterparts in 1961, with special reference to the questions raised by Demoulin. Finallv, in early 1963, during another visit to the Muséum, I made a final check on the specimen with reference to the drawings which accompany the present paper. ${ }^{3}$ In the following account I have attempted to redefine the family Triplosobidae as well as the genus, using terminology consistent with that employed in my previously published papers on fossil mayflies.

\section{Order Ephemeroptera \\ Family Triplosobidae Handlirsch, I906}

Fore and hind wings similar in form and venation; Rs having two intercalary veins and arising directly from R; MA free from Rs, unbranched. Abdomen slender, with prominent cerci and a median caudal filament.

\section{Genus Triplosoba Handlirsch, 1906}

Triplosoba Handlirsch, 1906, Foss. Ins.: 312 [pro Blanchardia Brongniart 1893: 325 (non Castleman, 1875)].

Since only one species of this genus is known, generic characters are assigned arbitrarily. It seems probable, however, that the brancied condition of MP, the presence of IMP, and the unbranched $\mathrm{CuA}$ are features of generic significance.

Type species: Blanchardia pulchella Brongniart

$$
\begin{gathered}
\text { Triplosoba pulchella (Brongniart) } \\
\text { Plate I4 }
\end{gathered}
$$

Blanchardia pulchella Brongniart, 1893, Recherches Hist. Ins. Foss.:328, fig. 14 ; pl. 18, fig. 8, 9.

Triplosoba pulchella Handlirsch, 1906, Foss. Ins.: 312, pl. 32, fig. 6, 7 ; Handlirsch, 1911, Congr. Intern. Entom.: 183, pl. 8, fig. 12; Lameere, 1917, Mus. Nat. Hist. Natur., Bull., 23 :103; Martynov, 1924, Rev. Russe Ent., 18 :158, fig. 3; Tillyard, 1932, Amer. Journ. Sci., $23: 101$, fig. 1; Demoulin, 1956, Inst. Roy. Sci. Nat. Belgique, Bull., 32 (14):1-8, fig. 1; pl. 1.

The type specimen is in the Institute de Paléontologie, Muséum National d'Histoire Naturelle, Paris. It consists of both counterparts, one represented (natural size) in Brongniart's figure 8, plate I 8 of his I 893 monograph, the other in his figure 9 ; these illustrations are reproduced in the present paper, on plate $\mathrm{I} 3$, figure $\mathrm{c}$, and plate $\mathrm{I} 4$,

\footnotetext{
${ }^{3}$ In connection with this most recent visit, I am indebted to Professor J. P. Lehman, Director of the Institut de Paléontologie of the Muséum, for placing the Commentry fossils at my disposal.
} 
figure a. ${ }^{4}$ The fossil consists of a nearly whole insect, with outstretched but somewhat distorted wings. Subsequent to Brongniart's study of the fossil, as noted by Lameere (1917), specimen I 8-8 was covered with shellac, which rendered the venation of that counterpart nearly invisible. The shellac was still on the fossil in 1938 when I examined the specimen, but it has subsequently been removed, so that the venational details are now discernible. The fore wing, not quite complete, is $2 \mathrm{Imm}$. long; the hind wing, complete, is $21 \mathrm{~mm}$. long and $7 \mathrm{~mm}$. wide. The body length excluding cerci is $25 \mathrm{~mm}$. In the following discussion I am using specimen I 8-9 for reference, this being the better of the two counterparts and the one on which Demoulin based his interpretation.

WIngs. The right fore wing is incompletely preserved (fig. c, plate 14), lacking the very base, the apex, and the distal parts of the posterior margin; however, most of the rest of the wing is clearly preserved and it shows no distortion. Demoulin was convinced from his study of photographs of the fossil that the wing was very broad and nearly triangular (fig. a, plate 13 ); he also believed that he could see the veins of this wing extending much further distally than they were indicated in the figures of Brongniart. I have been unable to find any indications of such extensions of the veins in the fossil itself; there are faint surface markings on the rock which Demoulin may have noted in the photograph, but these are features of the rock's matrix; an examination of the specimen shows that similar markings are visible on various parts of the rock containing the fossil, some of this being clearly below the right hind wing of the photograph reproduced in Demoulin's paper. Such markings are also present on the rock a considerable distance away from the fossil itself. Consequently, although the apical and posterior margins of the fore wing are not preserved, there is, in my opinion, no evidence whatsoever that the wing was significantly broader than the hind wing or that it was nearly triangular in shape. Demoulin also believed that he could see in the photograph at the base of the fore wing a short submarginal costa and a precostal space. Neither Brongniart nor Lameere noted such a structure and I find none in the fossil. In this wing the stem of Rs can be followed clearly to its point of origin from Rl but the stem of MA is not preserved, a piece of the matrix being broken away at this point. However, one certainly gets the impression from the condition in the specimen that the basal part of MA is close to Rs, although the two veins are not in contact.

\footnotetext{
${ }^{4}$ For convenience of reference these counterparts are subsequently designated in the present paper as specimens 18-8 and 18-9.
} 
The left fore wing (fig. $\mathrm{b}$, plate 14 ) shows less of the wing area than the right, lacking the distal third and most of the entire hind margin; however, the basal part of the wing is clearly preserved and there seems little distortion in the preserved part of the wing. I could find no indication of the part of the hind margin suggested in Demoulin's paper nor of the submarginal costa and precostal space which he indicates in the left fore wing. It is of interest to note, incidentally, that the anterior margin of the wing near the base shows clear indications of serrations, comparable to those which have been seen in some Palaeodictyoptera. The origins of $\mathrm{Rs}$ and $\mathrm{MA}$ can easily be seen in this wing: Rs arises directly from $R$, without contact with MA, which can be seen to arise from the basal part of $R$, just a short distance basal of the origin of Rs. It is possible, of course, that the stem of $M$ is actually parallel and in contact with $\mathrm{R}$ but it is not discernible in the fossil.

The left hind wing (fig. $\mathrm{d}$, plate $\mathrm{I} 4$ ) is very nearly completely preserved, lacking only a short piece of the anterior margin towards the middle line of the wing; it shows no distortion. I could find no sign in the fossil of the precostal space and and submarginal costa shown in Demoulin's figure. Rs can be seen clearly arising from $R$, as in the two fore wings but the basal part of $M A$ is very different in position from that in the other wings mentioned; basally it is more removed from Rs than in the fore wings and it appears to meet MP very close to the base of $M$ itself. There is no visible connection between MA and $R$ directly. The common stem $M$ appears to be very close to $R$ and may be in contact with it. The origins of $\mathrm{CuA}$ and $\mathrm{CuP}$ are not preserved; however, $\mathrm{CuA}$ shortly diverges away slightly from MP producing an unusually wide space and at about the same level $\mathrm{CuP}$ diverges towards $\mathrm{CuA}$, the two latter veins being almost in contact at that point. $\mathrm{CuA}$ and $\mathrm{CuP}$ subsequently diverge as they approach the wing margin.

The right hand wing is the most poorly preserved of all, showing distortion and folding. The longitudinal veins are irregularly distributed over the wing area. The origins of $\mathrm{Rs}$ and MA are not preserved but the proximal parts of these veins seem to be remote from each other as in the other hind wing.

As can be seen from the foregoing remarks, I am in agreement with Brongniart and Lameere that the fore and hind wings of Triplosoba were very similar in form and in venation. I believe that Brongniart's drawing, figure 9 of plate $I 8$, is reasonably accurate, although more cross veins are shown in his figure than are now discernible in the specimen. I think it is probable that the fore and hind wings differ 


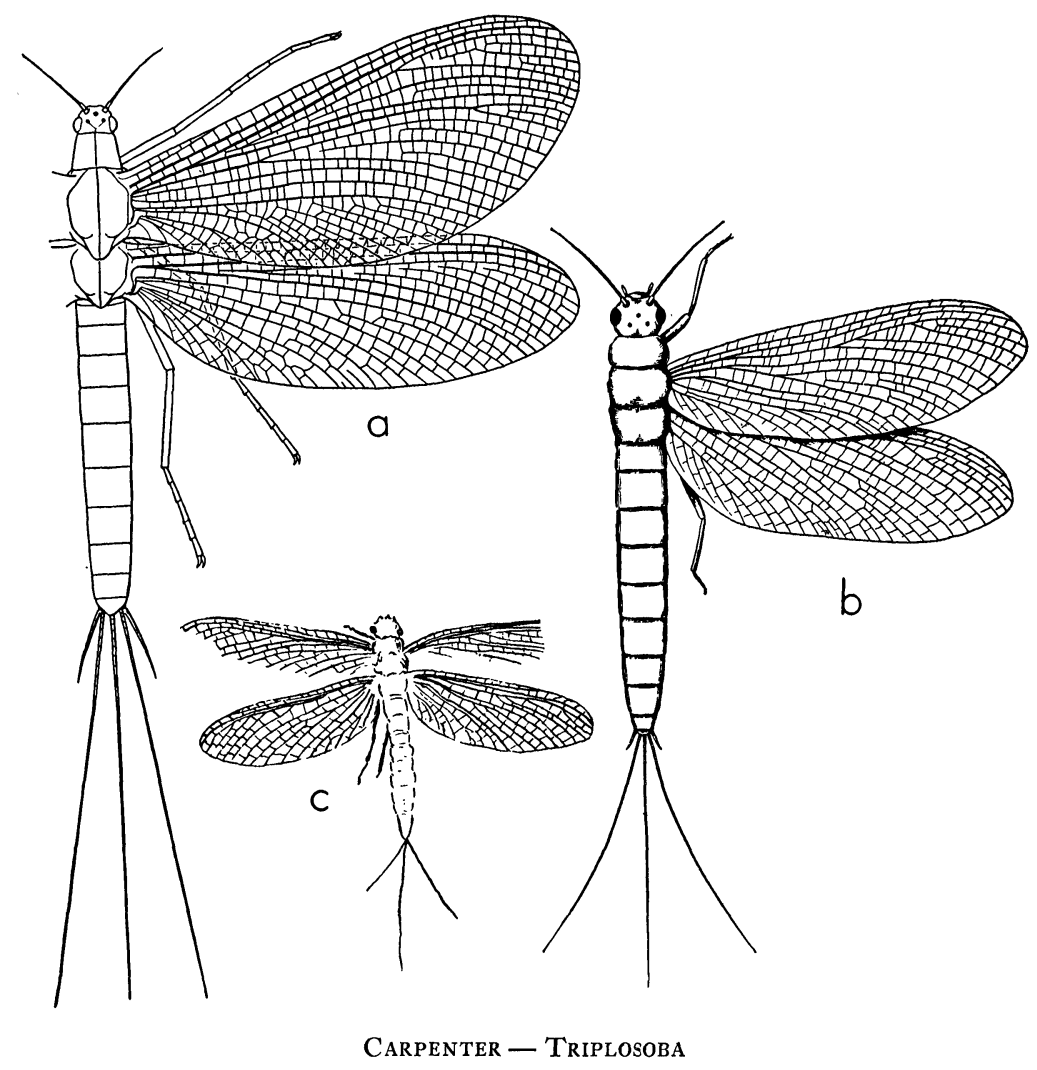


slightly in the origin of MA. As pointed out above, in both the fore wings the proximal part of MA is close to the proximal part of Rs and in the left fore wing MA can clearly be seen joining to $\mathrm{R}$. In the hind wings, on the other hand, MA is quite remote from Rs proximally and in the left hind wing it appears to join MP very close to the stem of $R$. These differences were recorded by Brongniart not only in his figure ( $18-9$ ) but in his description of the fossil, in which he states that although this vein in the anterior wing arises from the radius, in the posterior wing it arises from the very base of the wing. However, in his restoration of pulchella (fig. I 4, p. 327), he does not show MA joining $\mathrm{R}$ in the fore wing although he does represent MA as being closer to $R$ and $R s$ in the fore wing than in the hind wing. Handlirsch's figure (see fig. b, plate I3) of Triplosoba was taken from Brongniart's restoration in figure $\mathrm{I} 4$ rather than from his drawing of the fossil itself on plate $\mathrm{I} 8$; in the process Handlirsch apparently missed the difference between the fore and hind wings with respect to the origin of MA and its relationship to R and Rs. Similarly, Tillyard's drawing of a Triplosoba wing, adapted from $\mathrm{H}$ andlirsch, shows more nearly the condition of the hind wing but with the stem of $\mathrm{M}$ more remote from $\mathrm{R}$ than actually is the case. Demoulin's figure of the wing misses completely the difference in the position of MA with respect to $R s$ in the fore and hind wings; in fact, in his hind wing he shows MA actually closer to the base of Rs than it is represented in the fore wing.

BoDy. The body structure of Triplosoba is only vaguely preserved in the fossil. There is a suggestion of a head (which is interpreted by Demoulin as the prothorax), thorax and abdomen; three legs are indicated in the fossil, all of these being on the right side of the insect as preserved in counterpart I8-9. The segmentation of the legs is not clear and Demoulin's conclusion that the tarsi were five-segmented is unjustified. There is no question, however, as mentioned by Lameere ( I917) that there are three caudal processes, the two cerci and the median filament. As shown in Brongniart's figure of $18-8$ as well as in his restoration, figure $\mathrm{I} 4$, the median filament is much longer as preserved than it is in the cerci; this could of course be the result of the incomplete preservation of the latter. Demoulin has described and figured what he considers to be a gonostyle but actually the structure concerned is not part of the fossil; it is due entirely to an irregularity

Explanation of Plate 13

Triplosoba pulchella (Brongniart). a) restoration of Demoulin; b) restoration of Handlirsch; c) Brongniart's figure of counterpart 18-8. For further explanation see text. 

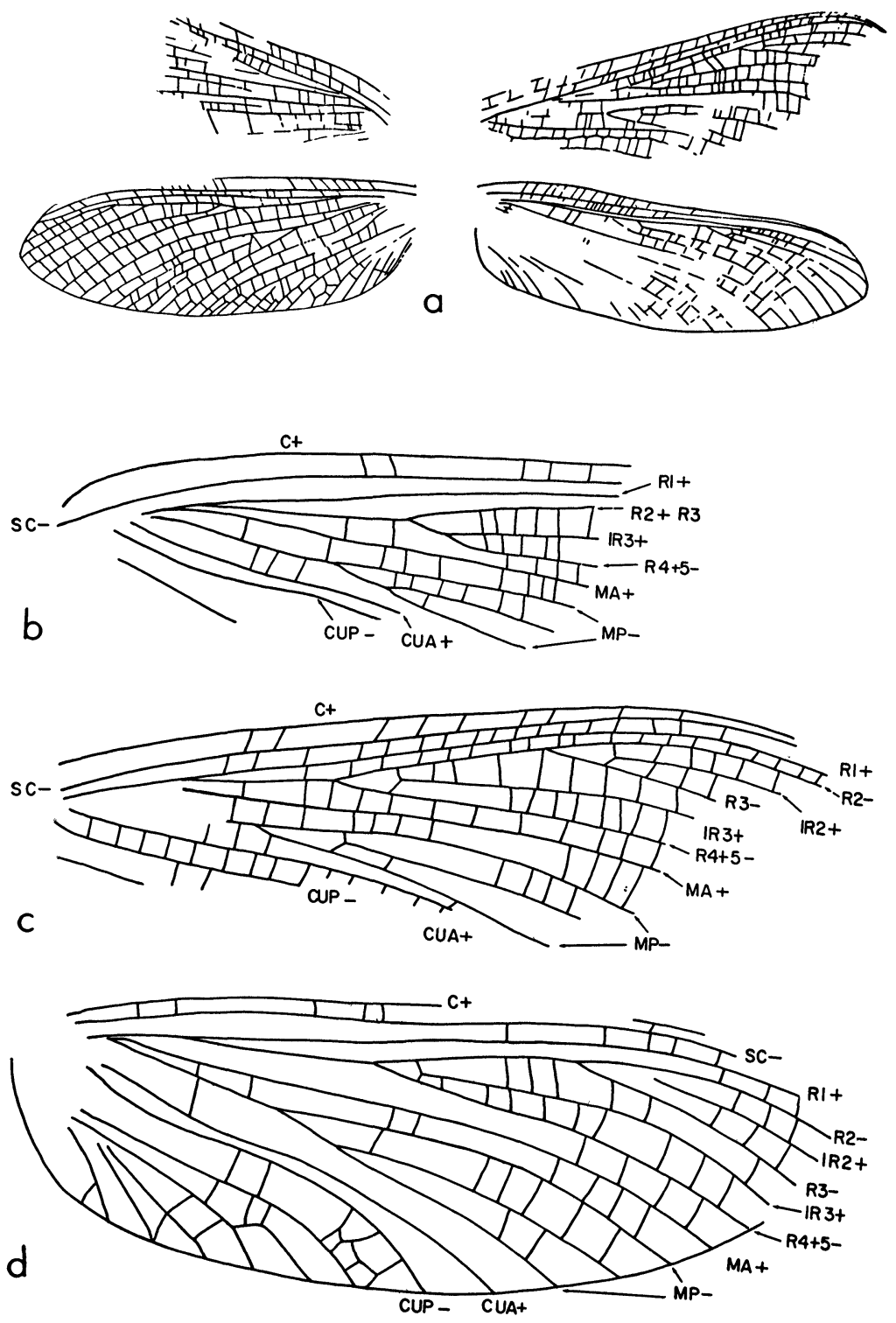

Carpenter - Triplosoba 
on the surface of the rock matrix as can be recognized easily from an examination of the fossil. Brongniart made no reference to such processes nor did Lameere. They were first shown by Handlirsch in his reconstruction but probably with no more reason than he showed ocelli, compound eyes, mouth-parts, antennae and tarsal claws, - none of which are even indicated in the fossil. ${ }^{5}$

\section{Probable Relationships of Triplosoba}

Triplosoba has nearly consistently been placed in the extinct Order Protephemerida, which was erected for it by Handlirsch in 1906. There are no other known genera of insects sufficiently close to Triplosoba to justify their inclusion in that order. However, the Permian Protereismatidae (and related families), which are accepted as true Ephemeroptera, tend to bridge the gap between Triplosoba and the Mesozoic and Recent mayflies. Inclusion of Triplosoba within the Ephemeroptera now seems more reasonable than it did in I906, especially if it be placed in a separate suborder (Protephemerida). This is in fact the suggestion made by Demoulin, although I am not in accord with the reasons which he gives for that proposal, i.e., the supposed triangulization of the fore wing and the beginning of reduction of the hind wing. The most distinctive characteristic of Triplosoba (so far as we now know) is the independence of MA from Rs in both wings. In the hind wings $M A$ is remote from $\mathrm{Rs}$ and seems to join MP directly near the base of the wing; in the fore wing MA is much closer to the base of Rs and actually coalesces with $\mathrm{R}$ without first joining MP. In all other Ephemeroptera, which may be regarded as comprising the suborder Euplectoptera, MA in both wings coalesces with Rs before diverging posteriorly and joining MP. In the Protereismatidae it diverges posteriorly again to meet MP but in Recent

\footnotetext{
${ }^{5}$ I seriously question the usefulness of such reconstructions as these given by Handlirsch and Demoulin in which there is no differentiation between structures actually preserved in the fossil and those which are merely assumed by the author to have been present. Such reconstructions are, in fact, often misleading since they give the general impression that the details shown are actually preserved.
}

\section{Explanation of Plate 14}

Triplosoba pulchella (Brongniart). All figures based on type counterpart 18-9. a) Brongniart's figure of counterpart $18-9$; b) original drawing of left fore wing; c) original drawing of right fore wing; d) original drawing of left hind wing, $C$, costa ; $R 1$, radius; $R 2, R 3, R 4+5$, branches of radial sector : IR2 and IR3, intercalary veins of radial sector; MA, anterior media; MP, posterior media, $\mathrm{CuA}$, anterior cubitus; $\mathrm{CuP}$, posterior cubitus; + , convex veins; - concave veins. 
families the origin of Rs (in the fore wing) has migrated basally to such an extent that this vein (Rs) is no longer attached to $R$, seeming to arise as a separate branch of $M$. So far as this trait is concerned, then, Triplosoba is more primitive than Protereismatidae or any other known mayflies. This is not to imply, of course, that the Triplosobidae were the ancestral stock from which the other Ephemeroptera arose; but they were also certainly a derivative of such a stock, having their own specializations.

\section{REFERENCES}

BRONGNIART, C.

1893 [1894]. Recherches pour servir à l'histoire des insectes fossiles des temps primaires. Soc. Industr. Minerale, Bull., $7: 124-615$, pls. 1753; also published as Thèse Fac. Sci. Paris, 821, pp. 1-494, pls. 1-37. (All page and plate citations in the present paper refer to the Thèse, since this is the only form of Brongniart's work usually available.)

Demoulin, G.

1956. Nouvelle recherches sur Triplosoba pulchella (Brongniart). Inst. Roy. Sci. Nat. Belgique, $32: 1-8$.

HANDLIRSCH, A.

1906. Die Fossilen Insekten, Wien.

LAMEERE, A.

1917. Revision sommaire des insectes fossiles du Stephanien de Commentry. Mus. Nat. Hist. Natur., Bull., 23 :141-201.

Martynov, A. V.

1924. The interpretation of the wing venation and tracheation of the Odonata and Agnatha. Rev. Russe Ent., 18:145-174 [Eng. transl., 1930, Psyche, $37: 245-280$.]

Tillyard, R. J.

1932. Kansas Permian insects. Part 15. The Order Plectoptera. Amer. Journ. Sci., 23 :97-134. 

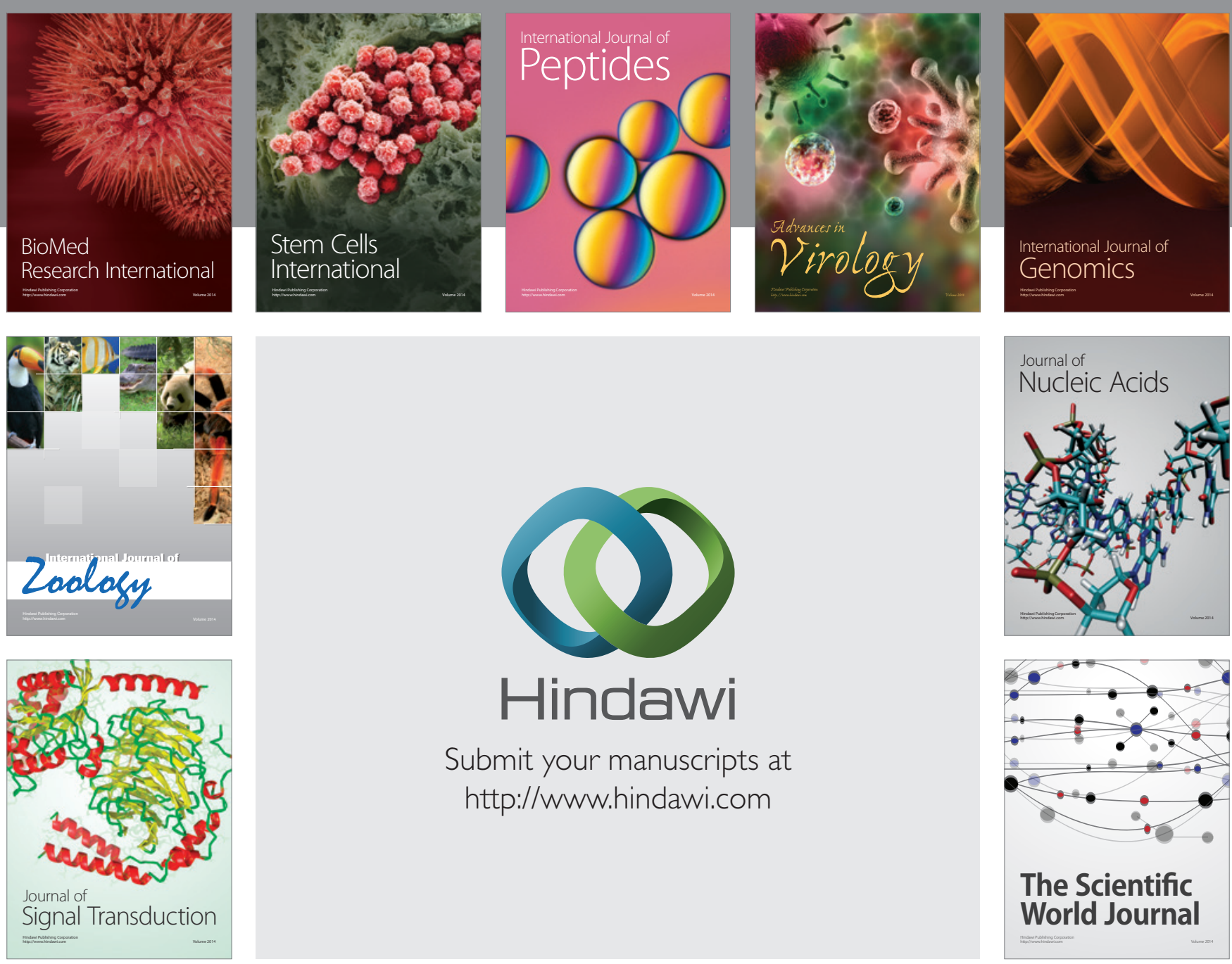

Submit your manuscripts at

http://www.hindawi.com
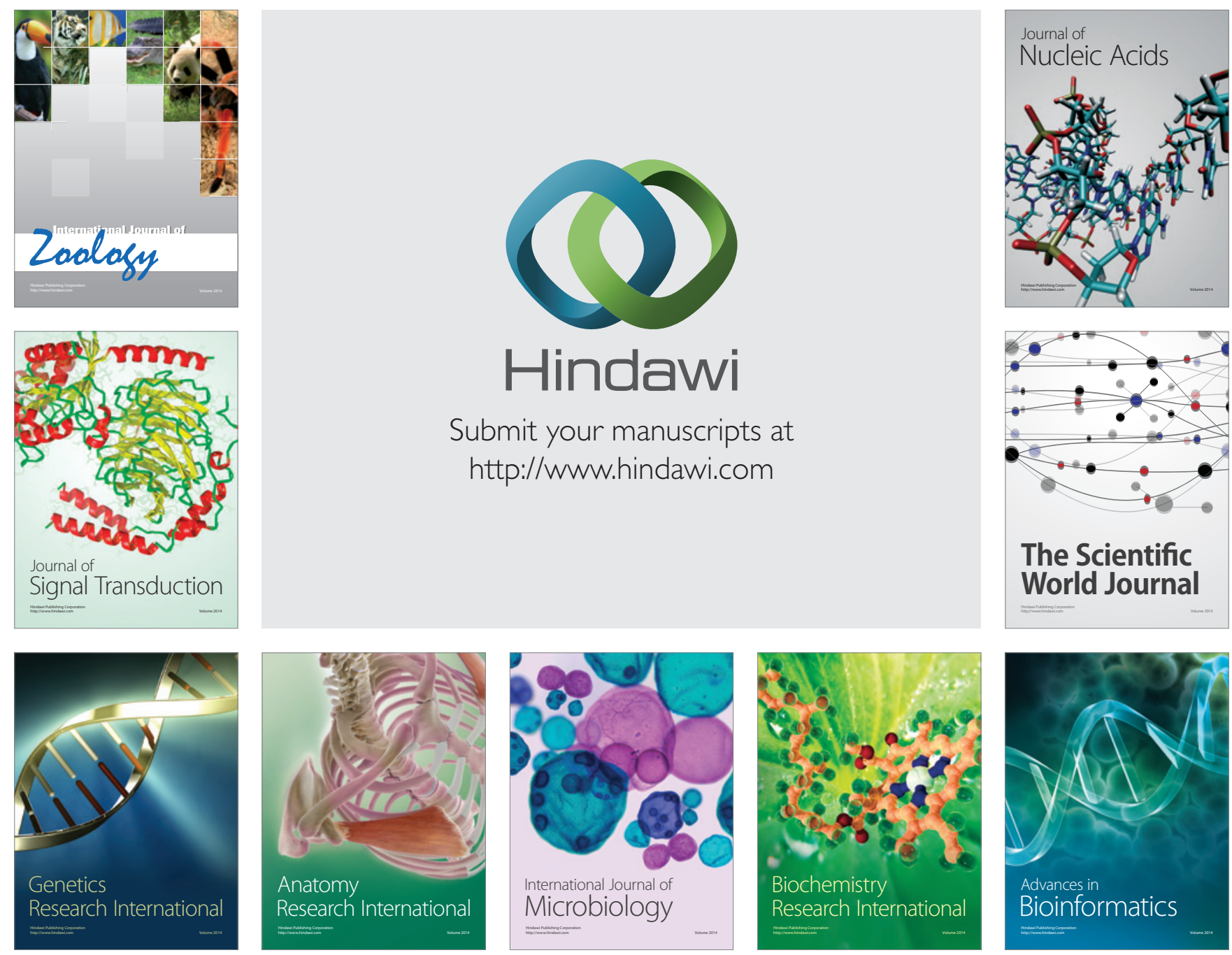

The Scientific World Journal
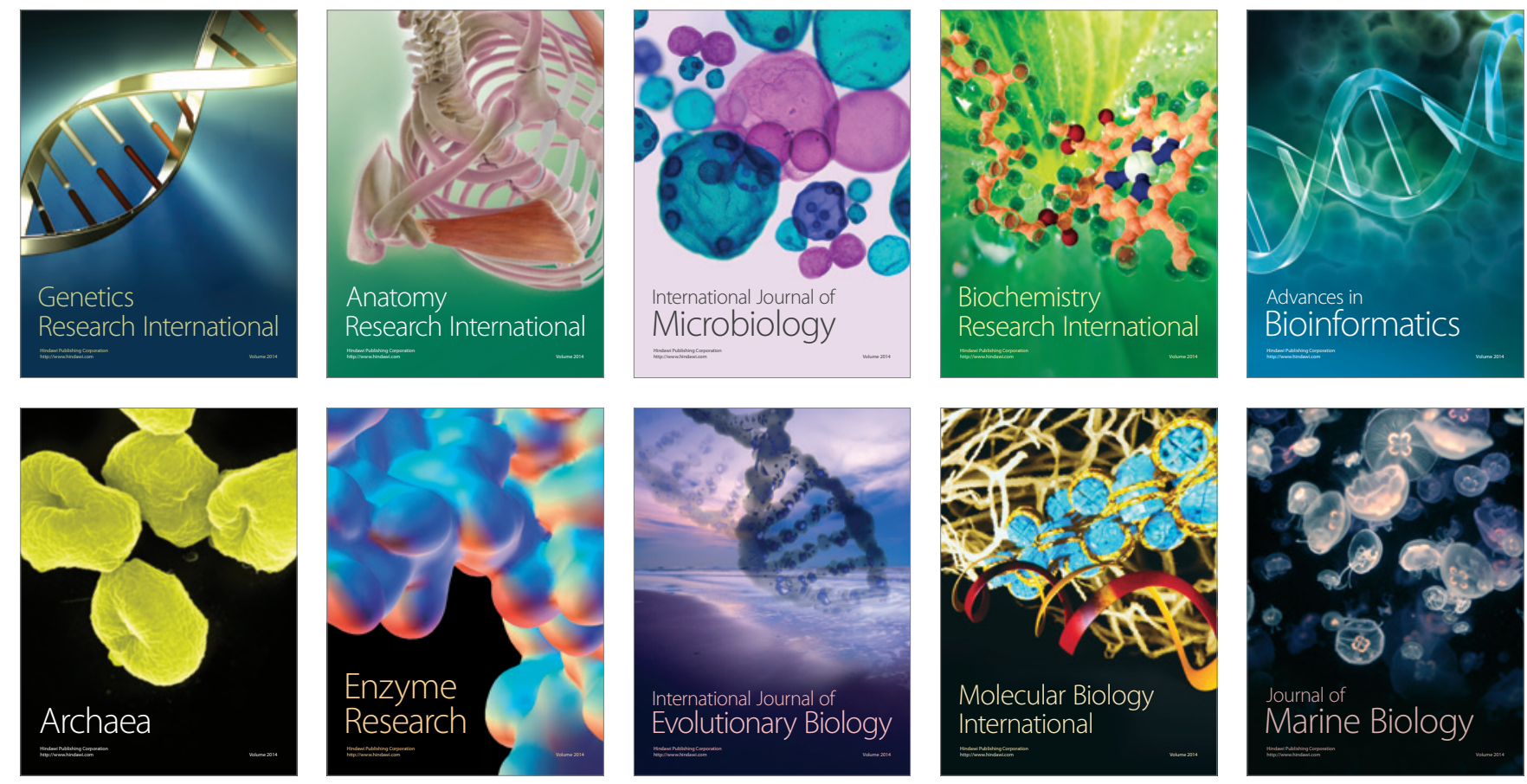